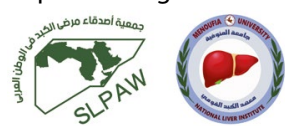

\title{
Risk stratification of patients
} fetoprotein model

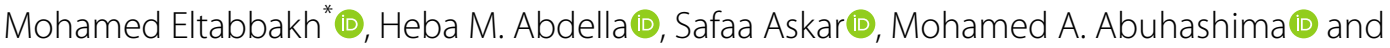 \\ Mohamed K. Shaker (B)
}

\begin{abstract}
Background: Hepatocellular carcinoma (HCC) is the fifth most common cancer worldwide. There are multiple factors that could affect the malignancy and progression of HCC including tumor number, size, and macrovascular invasion. The alpha-fetoprotein (AFP) model was validated as a predictor for HCC recurrence post-liver transplantation, especially in France. However, the AFP model has not been studied on patients with HCC undergoing locoregional treatment. This study aimed to assess the prognostic value of the AFP model in patients with HCC undergoing trans arterial chemoembolization (TACE). This cohort study was conducted at Ain Shams University Hospitals, Cairo, Egypt. We included all newly diagnosed patients with HCC who were fit for TACE from January 2012 to January 2017. The AFP model was calculated for each patient before TACE. Subsequently, we classified them into low- and high-risk groups for TACE. The patients were followed up by AFP level and triphasic spiral CT performed 1 month after TACE to evaluate the response then at 4 months and 7 months post TACE to evaluate the local and distant recurrence.
\end{abstract}

Results: One hundred and thirty-two patients were included in the study. Complete response (CR) was achieved nonsignificantly at a higher percentage in the low-risk group in comparison with the high-risk group. One- and threeyear recurrence-free survivals (RFS) were longer in the low-risk group in comparison with the high-risk group (50\% and $24.1 \%$ vs. $29.1 \%$ and $16.2 \%$, respectively). One- and three-year overall survival (OS) rates were $97 \%$ and $37.3 \%$ in the low-risk group vs. $98.1 \%$ and $11.6 \%$ in the high-risk group, respectively, without statistical significance. On classifying patients with AFP levels $<100 \mathrm{IU} / \mathrm{mL}$ into low- and high-risk patients, CR was achieved in a significantly higher percentage in the low-risk group in comparison with the high-risk group $(P<0.05)$. Recurrence occurred nonsignificantly in a less percentage in low than high-risk group. The median OS was significantly higher in the low-risk group in comparison with that in the high-risk group (18 vs. 16 months respectively) $(P<0.01)$.

Conclusion: The AFP model may have a prognostic value for patients with HCC undergoing TACE especially in patients with an AFP level $<100 \mathrm{IU} / \mathrm{mL}$.

Keywords: Hepatocellular carcinoma, Egypt, Alpha-fetoprotein model, Trans arterial chemoembolization, Response, Recurrence

*Correspondence: dr_mohamed_eltabbakh@med.asu.edu.eg

Tropical Medicine Department, Faculty of Medicine, Ain Shams University,

Cairo, Egypt 


\section{Background}

Hepatocellular carcinoma (HCC) is the fifth most common cancer and the second most frequent cause of cancer-related deaths worldwide [1]. In Egypt, HCC accounts for $23.81 \%$ of all malignancies and constitutes $70.48 \%$ of all liver tumors [2]. Hepatitis $\mathrm{C}$ virus (HCV) infection is the most common cause of HCC in Egypt with more than $92.5 \%$ of patients infected with genotype 4 [3-6]. There are different treatment modalities for HCC including curative measures like liver transplant, surgery, radiofrequency ablation, and other palliative measures like trans arterial chemoembolization (TACE) [7]. There are multiple factors that could affect the malignancy and progression of HCC including tumor number, size, and macrovascular invasion, which are evaluated by radiological imaging before treatment [8]. Prognosis is also affected by the degree of hepatic dysfunction, patient comorbidities, and tumor biology [9]. Recently, the French study group for liver transplantation reported on a new predictive model for HCC recurrence, called the alpha-fetoprotein (AFP) model. They added AFP level to tumor size and number of nodules at listing which increased the accuracy for predicting recurrence after liver transplantation, which was shown to be superior to the Milan criteria in predicting recurrence in patients with HCC. It was validated in a cohort of French patients followed prospectively under the control of the French organization for organ sharing [10]. Therefore, it was officially adopted in January 2013 in France for selecting HCC candidates for liver transplantation [10]. However, the AFP model has not been studied on patients with HCC undergoing locoregional treatment with respect to response to treatment and $\mathrm{HCC}$ recurrence.

\section{Methods}

The aim of the current study was to assess the prognostic value of the AFP model in patients with HCC undergoing TACE.

This retrospective cohort study was performed at the Tropical Medicine department at Ain Shams University Hospitals, Cairo, Egypt. The study was approved by the Research and Ethical Committee of Faculty of Medicine, Ain Shams University, Cairo, Egypt in accordance with local research governance requirements. We included all newly diagnosed patients with $\mathrm{HCC}$ who were fit for TACE according to the Barcelona Clinic Liver Cancer (BCLC) staging 2012 from January 2012 to January 2017. The enrolled patients had been followed up till death or till the end of the study in January 2020. All patients with extrahepatic metastasis, gross vascular invasion, Child class $C$ patients, BCLC stage $C$ or $D$, patients lost to follow-up, or patients with any other medical comorbidities as (heart failure, renal failure, respiratory failure, etc.) were excluded from the study. All included patients were subjected to:

\section{Pretreatment assessment}

1. Full personal history taking, thorough clinical examination and laboratory investigations including complete blood count, alanine aminotransferase, aspartate aminotransferase, alkaline phosphatase, serum bilirubin, serum albumin, prothrombin time, AFP level, $\mathrm{HCV}$ antibody $(\mathrm{Ab})$, hepatitis $\mathrm{B}$ surface antigen, and serum creatinine.

2. Radiological investigations: abdominal ultrasound: for liver size, echogenicity, presence of hepatic focal lesion and their size, site, and number with assessment of portal vein status. All cases underwent triphasic abdominal computed tomography (CT) scan to confirm the diagnosis of the HCC by the presence of arterial enhancement of the focal lesion followed by washout in the porto-venous and delayed phases. Magnetic resonance imaging abdomen with diffusion was ordered if CT criteria were inconclusive or atypical.

Subsequently, the AFP model was calculated for each patient in the study before TACE according to the following (simplified, user-friendly version of the AFP model) [8]:

1. Largest diameter of the hepatic focal lesion $(\leq 3 \mathrm{~cm}$, $3-6 \mathrm{~cm}$, and $>6 \mathrm{~cm}$ were points 0,1 , and 4 , respectively).

2. Number of nodules ( $1-3$ and $\geq 4$ were points 0 and 2 , respectively).

3. AFP levels $(\mathrm{IU} / \mathrm{mL}) \leq 100,100-1000$, and $>1000$ were points 0,2 , and 3 , respectively.

Then the patients were classified into two groups according to the AFP model: low-risk group for TACE (total points $\leq 2$ ) and high-risk group for TACE (total points of $>2$ ).

The patients were considered eligible for TACE when they had HCC with BCLC stage B. TACE was performed in our HCC unit in Ain Shams hospitals, Cairo, Egypt, which is considered a highly specialized unit established to provide appropriate care for Egyptian patients with HCC. All patients were followed up by AFP, laboratory investigations, and triphasic spiral CT performed 1 month after TACE to evaluate the response and then every 3 months to evaluate local and distant recurrence. The response criteria were defined using the modified 
Response Evaluation Criteria in Solid Tumors (mRECIST) [11] to assess hepatic or extrahepatic tumor. In mRECIST, complete response (CR) was defined by complete disappearance of any intra tumoral arterial enhancement in all target lesions. Partial response (PR) was defined as at least a 30\% decrease in the sum of diameters of viable (enhancement in the arterial phase) target lesions, taking as reference the baseline sum of the diameters of target lesions. Stationary disease (SD) was defined as any case that does not qualify for either PR or progressive disease. Progressive disease (PD) was defined as an increase of at least $20 \%$ in the sum of the diameters of viable (enhancing) target lesions, taking as reference the smallest sum of the diameters of viable (enhancing) target lesions recorded since treatment started. HCC recurrence was calculated in patients who achieved $\mathrm{CR}$ in the first follow-up.

At the end of the study, the calculated model was used to predict the response to treatment, HCC recurrence, and overall survival (OS) in low- and high-risk groups. Disease-free survival (DFS) was calculated from the time of the procedure to the time of disease recurrence. OS was calculated from the time of intervention to death or last follow-up visit.

\section{Data management and statistical analysis}

IBM SPSS statistics (V. 21.0, IBM Corp., USA, 2012) was used for data analysis. We used mean, standard deviation $( \pm \mathrm{SD})$, and range for parametric numerical data and median and interquartile range (IQR) for nonparametric numerical data. We used Student's $t$ test, Mann-Whitney $U$ test ( $U$ test), chi-squared test, Fisher's exact test, Kaplan-Meier survival analysis, and log-rank test in analytical statistics. The confidence interval (CI) was set to $95 \%$, and the margin of error accepted was set to $5 \%$. Therefore, the $P$ value was considered significant as follows: $P>0.05$, nonsignificant (NS); $P<0.05$, significant (S); and $P<0.01$, highly significant (HS).

\section{Results}

One hundred and thirty-two patients were included in the study with mean age $57.28 \pm 7.46$ years, male predominance (77.3\%) and HCV Ab-positive predominance (89.4\%). The mean level of total bilirubin was $1.14 \pm 0.45$ $\mathrm{mg} / \mathrm{dL}$, and the mean level of INR was $1.22 \pm 0.17$. The median AFP level was $39.5 \mathrm{IU} / \mathrm{mL}$ (IQR: 13.2-301.5). Seventy-nine patients (59.8\%) had AFP levels less than $100 \mathrm{IU} / \mathrm{mL}, 30$ patients (22.7\%) had AFP levels between 100 and $1000 \mathrm{IU} / \mathrm{mL}$, and 23 patients (17.4\%) had AFP levels more than $1000 \mathrm{IU} / \mathrm{mL}$. Most of the patients were Child A (119 patients (90.2\%)), while 13 patients (9.8\%) were Child B. As for BCLC staging, 64 patients (48.5\%) were $\mathrm{BCLC} A$, and 62 patients (47\%) were BCLC B. Their mean model for end-stage liver disease score was $9.83 \pm$ 2.6. Most of the patients were within Milan criteria (71 patients $(53.8 \%))$. The median number of nodules was 1 (range 1-6), while the mean size of the largest nodule was $4.32 \pm 1.99 \mathrm{~cm}$ (range $1-12 \mathrm{~cm}$ ).

One hundred and seven patients (81.1\%) achieved CR after TACE according to mRECIST, 21 patients (15.9\%) achieved PR, 2 patients (1.5\%) achieved SD, and 2 patients (1.5\%) had PD. Recurrence occurred in 80 patients $(74.8 \%)$ after intervention. The median OS was 18 months (SE 0.993 with 95\% CI 16.053 (lower) and 19.947 (upper)). One and three-year survival was $77 \%$ and $9.4 \%$, respectively. The median RFS was 6 months (SE 0.428 with 95\% CI 5.161 (lower) and 6.839 (upper)). The one and three-year RFS rates were 38\% and $7.7 \%$, respectively. In classifying our patients into Childs A and B, it was found that CR was achieved in a higher number of patients of Child class A (97 patients $(81.5 \%))$ than in Child class B (10 patients $(76.9 \%))$. PR occurred in a higher percentage of patients of Child class B (3 patients (23.1\%)) than Child class A (18 patients (15.1\%)). Two patients of Child class A had SD, but none of Child class B had SD or PD, all without reaching statistical significance $(P>0.05)$. Recurrence occurred in a higher percentage of patients of Child class B (9 patients (90\%)) than Child class A (71 patients (73.2\%)). The median OS in Child class A was 17 months (range 3-42 months), and 15 months (range 8-32 months) in Child class B. None of these results reached statistically significant differences between the two groups $(P>0.05)$.

Majority of our patients were classified as high-risk by the AFP model (75 patients (56.8\%)) (Table 1$)$.

Complete response was achieved in a higher percentage of patients in the low-risk group (52 patients (91.2\%)) than in the high-risk group (55 patients (73.3\%)). Conversely, PR occurred in a higher number of patients in the high-risk group (16 patients $(21.3 \%)$ ) than in the low-risk group (5 patients (8.8\%)). Two patients in the high-risk group had SD, and another

Table 1 Classification of patients according to the AFP model before TACE

\begin{tabular}{lll}
\hline AFP model & & $\boldsymbol{n}=\mathbf{1 3 2}$ \\
\hline Score & Median & 2 \\
Classification & Range & $0-7$ \\
& Low-risk & $57(43.2 \%)$ \\
& Median & 0 \\
Range & $0-1$ \\
& High-risk & $75(56.8 \%)$ \\
& Median & 3 \\
& Range & $2-7$ \\
\hline
\end{tabular}


Table 2 The AFP model as a predictor of response, recurrence, and survival in patients undergoing TACE

\begin{tabular}{llllll}
\hline TACE & & $\begin{array}{l}\text { Low-risk } \\
\boldsymbol{n}=\mathbf{5 7}\end{array}$ & $\begin{array}{l}\text { High-risk } \\
\boldsymbol{n}=\mathbf{7 5}\end{array}$ & P value & Sig. \\
\hline Response & Complete response & $52(91.2 \%)$ & $55(73.3 \%)$ & 0.057 & NS \\
& Partial response & $5(8.8 \%)$ & $16(21.3 \%)$ & & \\
& Stationary disease & $0(0.0 \%)$ & $2(2.7 \%)$ & & \\
& Progressive disease & $0(0.0 \%)$ & $2(2.7 \%)$ & & \\
Recurrence & No recurrence & $15(28.8 \%)$ & $12(21.8 \%)$ & 0.403 & NS \\
& Recurrence & $37(71.2 \%)$ & $43(78.2 \%)$ & & \\
& Range & $10-42$ & $3-32$ & & \\
Survival & Negative & $37(64.9 \%)$ & $59(78.7 \%)$ & 0.079 & NS \\
& Positive & $20(35.1 \%)$ & $16(21.3 \%)$ & & \\
\hline
\end{tabular}

NS Nonsignificant

two patients of the same group had PD. Recurrence occurred in a higher number of patients of the high-risk group (43 patients (78.2\%)) than in the low-risk group (37 patients $(71.2 \%)$ ). None of these reached statistically significant differences between the two groups (Table 2).

The median OS in the low-risk group was higher than that in the high-risk group (32 months vs. 29 months, respectively). The 1-year OS rate was nearly similar in both groups (97\% in the low-risk group and $98.1 \%$ in the high-risk group), while the 3-year OS rate was higher in the low-risk group than in the high-risk group (37.3\% vs. $11.6 \%)$ but without reaching statistical significance (Table 3) (Fig. 1).

Low-risk patients had a higher median RFS (12 months) than high-risk patients (6 months). The 1- and 3 -year RFS rates were higher in the low-risk group than in the high-risk group (50\% and $4.8 \%$ vs $27 \%$ and $0.0 \%$, respectively) (Table 4) (Fig. 2).

Patients with AFP levels less than $100 \mathrm{IU} / \mathrm{mL}$ achieved CR in $84.8 \%$ of patients. CR occurred in $73.5 \%$ in patients who had AFP levels between 100 and $1000 \mathrm{IU} / \mathrm{mL}$, and $78.9 \%$ in patients with AFP levels above $1000 \mathrm{IU} / \mathrm{mL}$. There was more recurrence in patients with AFP levels less than $100 \mathrm{IU} / \mathrm{mL}$ (49 patients $(73.1 \%)$ ) than in patients with AFP levels between 100 and $1000 \mathrm{IU} / \mathrm{mL}$ (21 patients $(84 \%))$. However, surprisingly, in AFP levels $>1000 \mathrm{IU} / \mathrm{mL}$, recurrence occurred in 10 patients representing $66.7 \%$ (Table 5).
In cases with AFP levels < 100, CR was achieved in a significantly higher number of patients in the lowrisk group (52 patients (91.2\%)) than in the high-risk group (16 patients $(69.6 \%)$ ) in contrast to PR which was achieved in a higher percentage of the high-risk group (4 patients (17.4\%)) than the low-risk group (5 patients $(8.8 \%))$ with only 2 patients of the high-risk group achieving SD and one patient achieving PD. Recurrence occurred in a lesser percentage of patients in the low-risk group (37 patients $(71.2 \%)$ ) than in the high-risk group (13 patients $(81.2 \%)$ ) but without reaching a statistically significant difference between the two groups. The median OS was significantly higher in the low-risk group (18 months) than in the high-risk group (16 months). The median RFS was higher in the low-risk group (13 months) than in the high-risk group (6 months) but without reaching a statistically significant difference between the two groups (Table 6).

On dividing Child A cases into 2 subgroups according to alpha-fetoprotein model, the median recurrencefree survival was significantly higher in the low-risk group $(P=0.028)$. Also, the median overall survival was highly significant among the low-risk group $(P=0.000)$ (Table 7).

On dividing Child B cases into 2 subgroups according to alpha-fetoprotein model, there was no statistical significance between the 2 groups regarding response and recurrence. Although the median recurrence-free survival and median overall survival were higher in the low-risk group, they did not reach statistical significance (Table 8).

On dividing BCLC A cases into 2 subgroups according to alpha-fetoprotein model, there was no statistical significance between the 2 groups regarding response and recurrence. Although the median recurrence-free survival and median overall survival were higher in the low-risk group, they did not reach statistical significance (Table 9).

On dividing BCLC B cases into 2 subgroups according to alpha-fetoprotein model, there was no statistical significance between the 2 groups regarding response and recurrence. Although the median recurrence-free survival was higher in the low-risk group, it did not reach statistical significance. Only the median overall survival

Table 3 Overall survival (OS) in low- and high-risk patients according to the AFP model

\begin{tabular}{|c|c|c|c|c|c|c|c|c|}
\hline \multirow[t]{2}{*}{ Risk level } & \multicolumn{2}{|c|}{ OS (months) } & \multicolumn{2}{|l|}{$95 \% \mathrm{Cl}$} & \multirow[t]{2}{*}{$P$ value } & \multirow[t]{2}{*}{ Sig. } & \multicolumn{2}{|c|}{ Survival (\%) at } \\
\hline & Median & SE & Lower & Upper & & & 1 year & 3 years \\
\hline Low-risk & 32 & 4.441 & 23.295 & 40.705 & $>0.05$ & NS & $97.00 \%$ & $37.30 \%$ \\
\hline High-risk & 29 & 6.169 & 16.908 & 41.092 & & & $98.1 \%$ & $11.6 \%$ \\
\hline
\end{tabular}

OS, Overall survival, NS nonsignificant, CI Confidence interval 


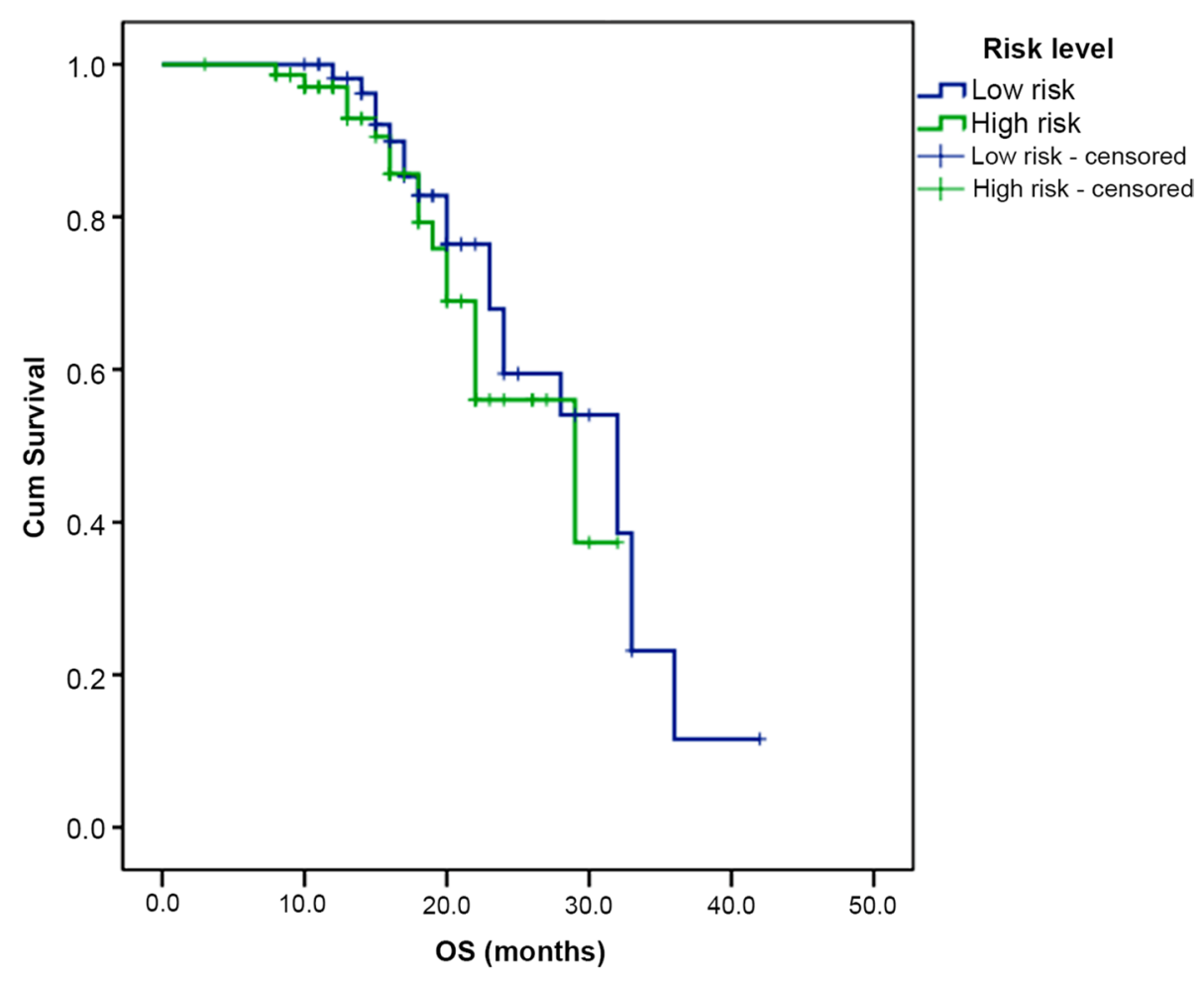

Fig. 1 Kaplan-Meier curve comparing overall survival in low- and high-risk patients

was significantly higher in the low-risk group $(P=0.003)$ (Table 10).

\section{Discussion}

HCC is the fifth most common cancer and the second most frequent cause of cancer-related deaths globally. It represents about $90 \%$ of primary liver cancers and is considered a major world health problem [1]. In Egypt, $\mathrm{HCC}$ is a significant public health problem and is responsible for $33.63 \%$ and $13.54 \%$ of all cancers in males and females, respectively [12].

The AFP model was proposed as a prognostic tool which was designed in a French training cohort of HCC candidates for liver transplantation and tested further in an external, prospectively followed, validation set. It has been shown to be more accurate than the Milan criteria for selecting $\mathrm{HCC}$ candidates for liver transplantation in the French population, and as a result, it was adopted as an official selection tool by the French organization for organ sharing in 2013 [10, 13]. However, to our knowledge, the AFP model has not been tested as a prognostic tool for patients with HCC undergoing TACE (with respect to response to treatment, $\mathrm{HCC}$ recurrence, and survival). Therefore, the present study is the first to assess the prognostic value of the AFP model in patients with HCC after TACE.

The mean age in our patients was around 58 years with male predominance (77.3\%). El-Zayadi et al. [14] reported that there was a slight shift in age distribution among Egyptian patients with $\mathrm{HCC}$ from $>60$ years to the age group 40-60 years. The relatively younger age in the Egyptian patients can be explained by the high prevalence of $\mathrm{HCV}$ among Egyptians and the occurrence of the infection at a young age. This is in agreement with other Egyptian studies which showed a shift in age in Egyptian

Table 4 Recurrence-free survival (RFS) in low- and high-risk patients

\begin{tabular}{|c|c|c|c|c|c|c|c|c|}
\hline \multirow[t]{2}{*}{ Risk level } & \multicolumn{2}{|c|}{ RFS (months) } & \multicolumn{2}{|l|}{$95 \% \mathrm{Cl}$} & \multirow[t]{2}{*}{$P$ value } & \multirow[t]{2}{*}{ Sig. } & \multicolumn{2}{|c|}{ Survival (\%) at } \\
\hline & Median & SE & Lower & Upper & & & 1 year & 3 years \\
\hline Low-risk & 12 & 1.989 & 8.101 & 15.899 & $>0.05$ & NS & $50.0 \%$ & $4.8 \%$ \\
\hline High-risk & 6 & 0.355 & 5.305 & 6.695 & & & $27.0 \%$ & $0.0 \%$ \\
\hline
\end{tabular}

RFS Recurrence-free survival, NS Nonsignificant, CI Confidence interval 


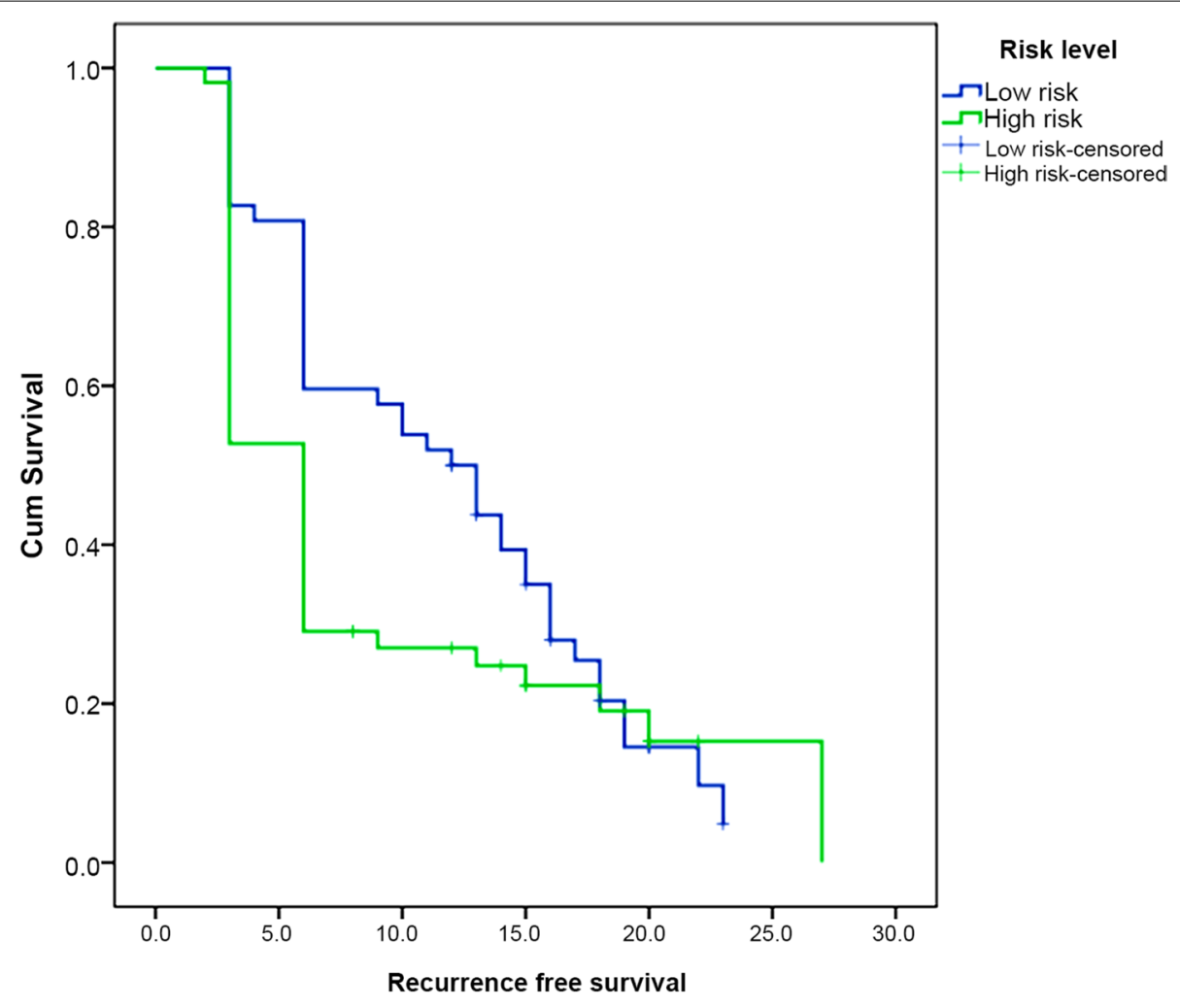

Fig. 2 Kaplan-Meier curve comparing recurrence-free survival in low- and high-risk patients

patients with HCC $[15,16]$. Most of the patients included were $\mathrm{HCV} \mathrm{Ab-positive} \mathrm{(89.4 \% ).} \mathrm{It} \mathrm{is} \mathrm{known} \mathrm{that} \mathrm{Egypt}$ has a high prevalence of HCV infection with $92.5 \%$ of patients infected with genotype 4 [3-6].

According to the latest European Association for the Study of the Liver (EASL) guidelines with respect to the locoregional treatment of HCC, thermal ablation with radiofrequency is the standard of care for patients with BCLC 0 and A tumors not suitable for surgery. Thermal ablation in single tumors $2-3 \mathrm{~cm}$ in size is an alternative to surgical resection based on technical factors, location of the tumor, and hepatic and extrahepatic conditions. TACE is recommended for patients with BCLC stage B and should be carried out in a selective manner [1]. An Egyptian study concluded that unresectable HCC with segmental vascular invasion could be treated with TACE with favorable outcome [17]. A proportion of patients in each stage do not fulfill all the criteria for the treatment allocation. In these cases, the patient should be offered the next most suitable option within the same stage or the next prognostic stage. This is already known by the concept of treatment stage migration [18]. Most of our

Table 5 Response and recurrence in different AFP levels in the studied patients

\begin{tabular}{|c|c|c|c|c|}
\hline & & \multicolumn{3}{|l|}{$\begin{array}{l}\text { TACE } \\
n=132\end{array}$} \\
\hline & & $\begin{array}{l}\text { AFP level } \\
<100 \mathrm{IU} / \mathrm{mL}\end{array}$ & $\begin{array}{l}\text { AFP level } \\
100-1000 \mathrm{IU} / \mathrm{mL}\end{array}$ & $\begin{array}{l}\text { AFP level } \\
>1000 \mathrm{IU} / \mathrm{mL}\end{array}$ \\
\hline & & $n=79$ & $n=34$ & $n=19$ \\
\hline \multirow[t]{4}{*}{ Response } & Complete response & $67(84.8 \%)$ & $25(73.5 \%)$ & $15(78.9 \%)$ \\
\hline & Partial response & $9(11.4 \%)$ & $9(26.5 \%)$ & $3(15.8 \%)$ \\
\hline & Stationary disease & $2(2.5 \%)$ & $0(0.0 \%)$ & $0(0.0 \%)$ \\
\hline & Progressive disease & $1(1.3 \%)$ & $0(0.0 \%)$ & $1(5.3 \%)$ \\
\hline \multirow[t]{2}{*}{ Recurrence } & No recurrence & $18(26.9 \%)$ & $4(16.0 \%)$ & $5(33.3 \%)$ \\
\hline & Recurrence & $49(73.1 \%)$ & $21(84.0 \%)$ & $10(66.7 \%)$ \\
\hline
\end{tabular}


Table 6 Response, recurrence, OS, RFS in patients with AFP levels $<100$ after classification into the low- and high-risk groups by the AFP model

\begin{tabular}{|c|c|c|c|c|c|}
\hline & & $\begin{array}{l}\text { Low-risk } \\
n=57\end{array}$ & $\begin{array}{l}\text { High-risk } \\
n=22\end{array}$ & $P$ value & Sig. \\
\hline \multirow[t]{4}{*}{ Response } & $\begin{array}{l}\text { Complete } \\
\text { response }\end{array}$ & $52(91.2 \%)$ & $16(69.6 \%)$ & $<0.05$ & S \\
\hline & Partial response & $5(8.8 \%)$ & $4(17.4 \%)$ & & \\
\hline & $\begin{array}{l}\text { Stationary } \\
\text { disease }\end{array}$ & $0(0.0 \%)$ & $2(8.7 \%)$ & & \\
\hline & $\begin{array}{l}\text { Progressive } \\
\text { disease }\end{array}$ & $0(0.0 \%)$ & $0(0.0 \%)$ & & \\
\hline \multirow[t]{2}{*}{ RFS (months) } & Median & 13 & 6 & $>0.05$ & NS \\
\hline & Range & $3-36$ & $3-30$ & & \\
\hline \multirow[t]{2}{*}{ Recurrence } & No recurrence & 15 (28.8\%) & $3(18.8 \%)$ & $>0.05$ & NS \\
\hline & Recurrence & $37(71.2 \%)$ & $13(81.2 \%)$ & & \\
\hline \multirow[t]{2}{*}{ OS (months) } & Median & 18 & 16 & $<0.01$ & $\mathrm{HS}$ \\
\hline & Range & $10-42$ & $3-30$ & & \\
\hline
\end{tabular}

RFS Recurrence-free survival, OS, Overall survival, NS Nonsignificant, $S$ Significant, HS Highly significant

patients were Child A (90.2\%). About $48.5 \%$ of the patients were BCLC A, and $47 \%$ were BCLC B. This is explained by the facts that some lesions were large $(>4 \mathrm{~cm})$ and others were located near the main bile duct, the intestinal loop, or a blood vessel, so radio frequency ablation could not be done, and TACE was the second-best option for them. This is compatible with stage migration in the treatment of HCC as documented in EASL practice guidelines 2018 concerning the management of HCC [1].

In the current study, $81.1 \%$ achieved CR, and recurrence occurred in about $74.8 \%$ of patients. Median OS was 18 months, while the 1 and 3-year OS were $77 \%$ and $9.4 \%$, respectively. The one and three-year RFS rates were $39 \%$ and $20 \%$, respectively. Lencioni et al., [18] published a systematic review on conventional TACE, which included 101 articles, with 10,108 patients. The objective response rate defined as the sum of CR and PR was $52.5 \%$, which is much less than that of the current study where the objective response rate was $97 \%(\mathrm{CR}=81.1 \%$, $\mathrm{PR}=15.9 \%$ ). The OS was $70.3 \%$ at 1 year which is less than that of the current study (77\%). The 3-year OS was also higher $(40.4 \%)$ than that in our study $(9.4 \%)$. The median OS was 19.4 months vs. 18 months in the current study. In a similar study [19], the tumor response in 129 patients with $\mathrm{HCC}$ was evaluated 3 months after the first TACE. In the conventional TACE group, the disease was controlled in $79.8 \%$ of patients, which is less than that of the current study where it was controlled in $98.5 \%$ of patients. CR was $23.1 \%$, which is much less than that in the current study (81.1\%). PR was $26.3 \%$ which was more than the current study (15.9\%). SD was also higher than that in the current study (30.4\% vs. $1.5 \%)$. PD occurred in $20.2 \%$ of the cases in contrast with the only $1.5 \%$ of the current study. Kloeckner et al. [20] reported that the median survival was 409 days (13.6 months) in the conventional TACE group, which is less than that of the current study (18 months).

In the current study, it was observed that the more the liver functions were impaired, the more the increase in the recurrence rate. Recurrence occurred in $73.2 \%$ of Child class A and in $90 \%$ of Child class B. The median OS was 17 months in Child class A and 15 months in Child class B. The 1- and 3-year OS were $77.9 \%$ and $10.3 \%$, respectively, in Child class $A$, and $69.2 \%$ and $0 \%$, respectively, in Child class B. This is compatible with an Egyptian study performed by Zeeneldin et al. [21] who studied 221 patients with HCC who underwent TACE in the

Table 7 Classifying Child A cases into low- and high-risk groups for TACE according to the AFP model

\begin{tabular}{|c|c|c|c|c|c|c|}
\hline & & \multicolumn{2}{|l|}{ Child A } & \multirow[t]{3}{*}{ Test value } & \multirow[t]{3}{*}{$P$ value } & \multirow[t]{3}{*}{ Sig. } \\
\hline & & Low-risk & High-risk & & & \\
\hline & & No. $=52$ & No. $=67$ & & & \\
\hline \multirow[t]{4}{*}{ Response } & Complete response & 48 (92.3\%) & $49(73.1 \%)$ & $7.799^{*}$ & 0.050 & NS \\
\hline & Partial response & $4(7.7 \%)$ & $14(20.9 \%)$ & & & \\
\hline & Stationary disease & $0(0.0 \%)$ & $2(3.0 \%)$ & & & \\
\hline & Progressive disease & $0(0.0 \%)$ & $2(3.0 \%)$ & & & \\
\hline \multirow[t]{2}{*}{ Recurrence } & No recurrence & $15(31.2 \%)$ & $11(22.4 \%)$ & $0.957^{*}$ & 0.328 & NS \\
\hline & Recurrence & $33(68.8 \%)$ & $38(77.6 \%)$ & & & \\
\hline \multirow[t]{2}{*}{ Recurrence-free survival } & Median (IQR) & $13(6-18)$ & $6(3-16)$ & $-2.198 \neq$ & 0.028 & S \\
\hline & Range & $3-36$ & $3-30$ & & & \\
\hline \multirow[t]{2}{*}{ OS (months) } & Median (IQR) & $18.5(15.5-24.5)$ & $16(10-20)$ & $-3.713 \neq$ & 0.000 & $\mathrm{HS}$ \\
\hline & Range & $10-42$ & $3-30$ & & & \\
\hline
\end{tabular}


Table 8 Classifying Child B cases into low- and high-risk groups for TACE according to the AFP model

\begin{tabular}{|c|c|c|c|c|c|c|}
\hline & & \multicolumn{2}{|l|}{ Child B } & \multirow[t]{3}{*}{ Test value } & \multirow[t]{3}{*}{$P$ value } & \multirow[t]{3}{*}{ Sig. } \\
\hline & & Low-risk & High-risk & & & \\
\hline & & No. $=5$ & No. $=8$ & & & \\
\hline \multirow[t]{4}{*}{ Response } & Complete response & $4(80.0 \%)$ & $6(75.0 \%)$ & $0.043^{*}$ & 0.835 & NS \\
\hline & Partial response & $1(20.0 \%)$ & $2(25.0 \%)$ & & & \\
\hline & Stationary disease & $0(0.0 \%)$ & $0(0.0 \%)$ & & & \\
\hline & Progressive disease & $0(0.0 \%)$ & $0(0.0 \%)$ & & & \\
\hline \multirow[t]{2}{*}{ Recurrence } & No recurrence & $0(0.0 \%)$ & $1(16.7 \%)$ & $0.741^{*}$ & 0.389 & NS \\
\hline & Recurrence & $4(100.0 \%)$ & $5(83.3 \%)$ & & & \\
\hline \multirow[t]{2}{*}{ Recurrence-free survival } & Median (IQR) & $12(6-17)$ & $4.5(3-15)$ & $-0.829 \neq$ & 0.407 & NS \\
\hline & Range & $3-24$ & $3-29$ & & & \\
\hline \multirow[t]{2}{*}{ OS (months) } & Median (IQR) & $18(15-22)$ & $12.5(9-25.5)$ & $-0.882 \neq$ & 0.378 & NS \\
\hline & Range & $13-24$ & $8-32$ & & & \\
\hline
\end{tabular}

period between January 2007 and December 2010 and reported that the median OS in Child A was 21 months, which is more than that of the current study (17 months), and 11 months in Child B, which is less than that of the current study (15 months). The results of the current study are close to that of Kloeckner et al. [20] who found that the median OS of the subgroup of Child A patients, was 602 days for conventional TACE, which is equal to 20 months. Moreover, the results of the current study are very close to that of Greten et al. [22], which had the same median OS in Child A patients as that of the current study (17 months), while patients with Child $B$ had a lower median survival rate of 6 months vs. 14.5 months in the current study.

Prognosis after locoregional treatment is affected by many factors including degree of hepatic dysfunction, patient comorbidities, tumor biology, level of AFP, number of nodules, and size of largest nodule [8, 9]. Several studies used the AFP level alone as a prognostic factor for
HCC post intervention like Riaz et al.'s [23] which studied 125 patients with baseline AFP higher than $200 \mathrm{ng} / \mathrm{mL}$ and found that a 50\% decrease in AFP levels resulted in a better time to progression and OS in comparison with patients whose AFP levels failed to respond to treatment with TACE or trans arterial radioembolization; another study also evaluated the percentage decline in tumor marker levels after treatment (from pretreatment levels) in patients who underwent TACE [24]. The reductions in both AFP and PIVKA-II levels in patients exhibiting a CR or PR were significantly greater than that in those with SD or PD according to the mRECIST criteria. They also found significant differences in median OS times between tumor marker responders and nonresponders.

Several studies used the tumor size [25-27] and number of tumor nodules $[28,29]$ as predictors of response, recurrence, and survival for HCC after locoregional treatment. Others used the AFP level in combination

Table 9 Classifying BCLC A cases into low- and high-risk groups for TACE according to the AFP model

\begin{tabular}{|c|c|c|c|c|c|c|}
\hline & & \multicolumn{2}{|l|}{ BCLC A } & \multirow[t]{3}{*}{ Test value } & \multirow[t]{3}{*}{$P$ value } & \multirow[t]{3}{*}{ Sig. } \\
\hline & & Low-risk & High-risk & & & \\
\hline & & No. $=38$ & No. $=26$ & & & \\
\hline \multirow[t]{4}{*}{ Response } & Complete response & $35(92.1 \%)$ & $20(76.9 \%)$ & $2.944^{*}$ & 0.086 & NS \\
\hline & Partial response & $3(7.9 \%)$ & $6(23.1 \%)$ & & & \\
\hline & Stationary disease & $0(0.0 \%)$ & $0(0.0 \%)$ & & & \\
\hline & Progressive disease & $0(0.0 \%)$ & $0(0.0 \%)$ & & & \\
\hline \multirow[t]{2}{*}{ Recurrence } & No recurrence & $9(25.7 \%)$ & $7(35.0 \%)$ & $0.532^{*}$ & 0.466 & NS \\
\hline & Recurrence & $26(74.3 \%)$ & $13(65.0 \%)$ & & & \\
\hline \multirow[t]{2}{*}{ Recurrence-free survival } & Median (IQR) & $12.5(6-17)$ & $8.5(3-16)$ & $-1.177 \neq$ & 0.239 & NS \\
\hline & Range & $3-36$ & $3-27$ & & & \\
\hline \multirow[t]{2}{*}{ OS (months) } & Median (IQR) & $18(15-22)$ & $16(12-22)$ & $-1.452 \neq$ & 0.146 & NS \\
\hline & Range & $10-42$ & $8-32$ & & & \\
\hline
\end{tabular}


Table 10 Classifying BCLC B cases into low- and high-risk groups for TACE according to the AFP model

\begin{tabular}{|c|c|c|c|c|c|c|}
\hline & & \multicolumn{2}{|l|}{ BCLC B } & \multirow[t]{3}{*}{ Test value } & \multirow[t]{3}{*}{$P$ value } & \multirow[t]{3}{*}{ Sig. } \\
\hline & & Low-risk & High-risk & & & \\
\hline & & No. $=14$ & No. $=53$ & & & \\
\hline \multirow[t]{4}{*}{ Response } & Complete response & $12(85.7 \%)$ & $34(70.8 \%)$ & $1.730^{*}$ & 0.630 & NS \\
\hline & Partial response & $2(14.3 \%)$ & $10(20.8 \%)$ & & & \\
\hline & Stationary disease & $0(0.0 \%)$ & $2(4.2 \%)$ & & & \\
\hline & Progressive disease & $0(0.0 \%)$ & $2(4.2 \%)$ & & & \\
\hline \multirow[t]{2}{*}{ Recurrence } & No recurrence & $4(33.3 \%)$ & $5(14.7 \%)$ & $1.956^{*}$ & 0.162 & NS \\
\hline & Recurrence & $8(66.7 \%)$ & $29(85.3 \%)$ & & & \\
\hline \multirow[t]{2}{*}{ Recurrence-free survival } & Median (IQR) & $12.5(3-21)$ & $6(3-13)$ & $-0.934 \neq$ & 0.351 & NS \\
\hline & Range & $3-32$ & $3-30$ & & & \\
\hline \multirow[t]{2}{*}{ OS (months) } & Median (IQR) & $21(14-28)$ & $13(10-19)$ & $-2.936 \neq$ & 0.003 & $\mathrm{HS}$ \\
\hline & Range & $11-32$ & $3-30$ & & & \\
\hline
\end{tabular}

with the size of nodules as prognostic factors like $L a i$ et al [30] who suggested that the combination of the total tumor diameter $\leq 8 \mathrm{~cm}$ and an AFP level $\leq 400 \mathrm{ng} / \mathrm{mL}$ would result in favorable survival outcomes. The 5-year DFS rate was $74.4 \%$.

Others used the AFP level in combination with the number of nodules to assess the outcome after locoregional treatment, like Shin et al. [31], who found that tumor size $(\leq 5 \mathrm{~cm})$ and single nodularity were predictive factors for $\mathrm{CR}$, and multi-nodularity and elevated levels of AFP (> $20 \mathrm{ng} / \mathrm{mL}$ ) were predictive factors for recurrence after $C R$ in patients who underwent TACE as a first-line therapy. Another study of 357 patients with HCC who underwent radiofrequency ablation for primary HCC between 2001 and 2013 showed that male sex, AFP level (> $10 \mathrm{mg} / \mathrm{mL}$ ), and multiple tumors were significantly correlated with a high rate of HCC recurrence after complete ablation [32].

The AFP model was used to predict recurrence after liver transplantation for patients with HCC. In general, recurrence was higher in high-risk patients than in lowrisk patients. It was found that among 432 patients fulfilling the Milan criteria, the 5-year risk of recurrence was $12.8 \%$ in patients with a low-risk AFP model and $32.4 \%$ in patients with a high-risk AFP model. In the same study, of 142 patients beyond the Milan criteria, the risk of recurrence was $14.9 \%$ among patients with a low-risk AFP model and $58.9 \%$ in patients with a highrisk AFP model [13]. Further, another study assessed the AFP model as a predictor of recurrence in patients with HCC who underwent liver transplantation and found that low-risk patients showed $21.1 \%$ of 5 -year recurrence rate, which was lower than that of high-risk patients who showed $57.7 \%$ of 5 -year recurrence rate [33].
To our knowledge, no study evaluated the AFP model as a prognostic model for patients undergoing locoregional treatment for HCC. In the current study, we used the AFP model with its components: AFP level in combination with the size of the largest nodule and the number of nodules as a prognostic model for predicting response, recurrence, and survival in patients with $\mathrm{HCC}$ after TACE. In the current study, in low-risk patients according to the AFP model, recurrence was lower (71.2\%) than in the high-risk group (78.2\%). When we classified the cases, who underwent TACE with AFP level $<100 \mathrm{IU} / \mathrm{mL}$ according to the AFP model, recurrence was less in the low-risk group (37 patients $(71.2 \%))$ than it was in the high-risk group (13 patients (81.2\%)). Jinsoo et al. also assessed the AFP model as predictor of survival in patients with HCC who underwent liver transplantation and found that low-risk patients had a 5-year survival rate higher than that of high-risk patients (76.2\% vs. $52.2 \%$, respectively) [33]. In our patients, the 3-year survival in the low-risk group was higher than that in the high-risk group ( $37.3 \%$ vs. $11.6 \%$, respectively). Our study is the first that has tried to predict the response, recurrence, and survival after TACE depending on three parameters (level of AFP, number of nodules, and size of largest nodule collectively) in the form of the AFP model, which was recently validated for patients with HCC undergoing liver transplantation by the French group [10]. More studies are still needed with larger sample sizes to validate its use. Further comparative studies between the AFP model and other prognostic scores for patients with HCC who will perform TACE are needed to figure out the best predictors of response, recurrence, and survival. Further prospective studies are still needed on the efficacy of the AFP model in predicting recurrence and survival in patients with vascular invasion who are candidates for locoregional treatment. 


\section{Conclusion}

The AFP model may have a prognostic value as a predictor of response, recurrence, and survival in patients with HCC undergoing TACE, especially in patients with AFP levels less than $100 \mathrm{IU} / \mathrm{mL}$; however, more studies with larger sample sizes are needed to validate its use. We may recommend a strict program and shorter periods for follow-up for high-risk groups for TACE according to the AFP model as they may have a worse prognosis (in the term of response, recurrence, and survival) than low-risk groups.

\begin{abstract}
Abbreviations
HCC: Hepatocellular carcinoma; AFP: Alpha-fetoprotein; TACE: Trans arterial chemoembolization; mRECIST: Modified response evaluation criteria in solid tumors; CR: Complete response; PR: Partial response; SD: Stationary disease; PD: Progressive disease; OS: Overall survival; DFS: Disease-free survival.
\end{abstract}

\section{Acknowledgements}

Not applicable

\section{Authors' contributions}

ME designed and coordinated the study; ME and HMA analyzed the data; ME and MAA interpreted the data; ME and SA wrote the manuscript; ME and MKS revised the article; all authors approved the final version of the article.

\section{Funding}

The authors declare that they have no known competing financial interests or personal relationships that could have appeared to influence the work reported in this paper.

\section{Availability of data and materials}

All data generated or analyzed during this study are included in this published article.

\section{Declarations}

\section{Ethics approval and consent to participate}

The study was approved by the Research and Ethical Committee of Faculty of Medicine, Ain Shams University, Cairo, Egypt in accordance with local research governance requirements (FMASU R 66/2021).

\section{Consent for publication}

Not applicable

\section{Competing interests}

All authors declare that there are no conflicts of interest that could have appeared to influence the work reported in this paper.

Received: 27 June 2021 Accepted: 7 November 2021

Published online: 26 November 2021

\section{References}

1. Galle PR, Forner A, Llovet JM, Mazzaferro V, Piscaglia F, Raoul J, Schirmacher P, Vilgrainet V (2018) European Association for the Study of the liver. Electronic address: easloffice@easloffice.eu; European Association for the Study of the liver. EASL clinical practice guidelines: management of hepatocellular carcinoma. J Hepatol 69(1):182-236. https://doi.org/ 10.1016/j.jhep.2018.03.019 [ PMID: 29628281]. Erratum in: J Hepatol. 2019;70(4):817
2. Forner A, Llovet JM, Bruix J (2012) Chemoembolization for intermediate HCC: is there proof of survival benefit? J Hepatol 56(4):984-986PMID: 22008737. https://doi.org/10.1016/j.jhep.2011.08.017

3. Simmonds P, Alberti A, Alter HJ, Bonino F, Bradley DW, Brechot C, Brouwer JT, Chan SW, Chayama K, Chen DS (1994) A proposed system for the nomenclature of hepatitis C viral genotypes. Hepatology 19(5):13211324PMID: 8175159. https://doi.org/10.1002/hep.1840190538

4. Smith DB, Bukh J, Kuiken C, Muerhoff AS, Rice CM, Stapleton JT, Simmonds P (2014) Expanded classification of hepatitis C virus into 7 genotypes and 67 subtypes: updated criteria and genotype assignment web resource. Hepatology 59:318-327PMID: 24115039. https://doi.org/ 10.1002/hep.26744

5. Polaris Observatory HCV Collaborators (2017) Global prevalence and genotype distribution of hepatitis C virus infection in 2015: a modelling study. Lancet Gastroenterol Hepatol 2:161-176. https://doi.org/10.1016/ S2468-1253 [PMID: 28404132] (16); 30181-30189

6. Kouyoumjian SP, Chemaitelly H, Abu-Raddad LJ (2018) Characterizing hepatitis C virus epidemiology in Egypt: systematic reviews, meta-analyses, and meta-regressions. Sci Rep 8(1):1661[PMID: 29374178]. https://doi. org/10.1038/s41598-017-17936-4

7. Kohles N, Nagel D, Jüngst D, Durner J, Stieber P, Holdenrieder S (2012) Prognostic relevance of oncological serum biomarkers in liver cancer patients undergoing transarterial chemoembolization therapy. Tumour Biol 33(1):33-40PMID: 21931992. https://doi.org/10.1007/ s13277-011-0237-7

8. Duvoux C, Roudot-Thoraval F, Decaens T, Pessione F, Badran H, Piardi T, Francoz C, Compagnon P, Vanlemmens C, Dumortier J, Dharancy S, Gugenheim J, Bernard PH, Adam R, Radenne S, Muscari F, Conti F, Hardwigsen J, Pageaux GP, Chazouillères O, Salame E, Hilleret MN, Lebray P, Abergel A, Debette-Gratien M, Kluger MD, Mallat A, Azoulay D, Cherqui D, Liver Transplantation French Study Group (2012) Liver transplantation for hepatocellular carcinoma: a model including a-fetoprotein improves the performance of Milan criteria. Gastroenterology 143(4):986-994PMID: 22750200. https://doi.org/10.1053/j.gastro.2012.05.052

9. Sarkar J, DeLeon T, Wong LL (2017) MELD score and AST-to-platelet ratio index (APRI) predict long-term survival in patients with a small hepatocellular carcinoma following non-transplant therapies: a pilot study. Hepatoma Res 3:79-85PMID: 29075672. https://doi.org/10.20517/23945079.2017.06

10. Notarpaolo A, Layese R, Magistri P, Gambato M, Colledan M, Magini G, Miglioresi L, Vitale A, Vennarecci G, Ambrosio CD, Burra P, Di Benedetto F, Fagiuoli S, Colasanti M, Maria Ettorre G, Andreoli A, Cillo U, Laurent A, Katsahian S, Audureau E, Roudot-Thoraval F, Duvoux C (2017) Validation of the AFP model as a predictor of HCC recurrence in patients with viral hepatitis-related cirrhosis who had received a liver transplant for HCC. J Hepatol 66(3):552-559PMID: 27899297. https://doi.org/10.1016/j.jhep. 2016.10.038

11. Lencioni R, Llovet JM (2010) Modified RECIST (mRECIST) assessment for hepatocellular carcinoma. Semin Liver Dis 30(1):52-60PMID: 20175033. https://doi.org/10.1055/s-0030-1247132

12. Elghazaly H, Gaballah A, Bahie EN (2018) Clinic-pathological pattern of hepatocellular carcinoma (HCC) in Egypt. Ann Oncol 29. https://doi.org/ 10.1093/annonc/mdy151.018

13. Ren A, Li Z, Zhou X, Zhang X, Huang X, Deng R, Ma Y (2020) Evaluation of the alpha-fetoprotein model for predicting recurrence and survival in patients with hepatitis B virus (HBV)-related cirrhosis who received liver transplantation for hepatocellular carcinoma. Front Surg 21(7):52PMID: 32974380. https://doi.org/10.3389/fsurg.2020.00052

14. El-Zayadi AR, Badran HM, Barakat EM, Mel-D A, Shawky S, Mohamed MK, Selim O, Saeid A (2005) Hepatocellular carcinoma in Egypt: a single center study over a decade. World J Gastroenterol 11(33):5193-5198PMID: 16127751. https://doi.org/10.3748/wjg.v11.i33.5193

15. Shaker MK, Abdella HM, Khalifa MO, El Dorry AK (2013) Epidemiological characteristics of hepatocellular carcinoma in Egypt: a retrospective analysis of 1313 cases. Liver Int 33(10):1601-1606PMID: 23714212. https:// doi.org/10.1111/liv.12209

16. Rashed WM, Kandeil MAM, Mahmoud MO, Ezzat S (2020) Hepatocellular carcinoma (HCC) in Egypt: a comprehensive overview. J Egypt Natl Canc Inst 32(1):5PMID: 32372179. https://doi.org/10.1186/s43046-020-0016-x

17. Abdella H, Shaker MK, Montasser IF, Sobhi M, Aly H, Sayed A, Saleh S, El Dorry A (2018) Outcome of transarterial chemoembolization in Egyptian 
patients with hepatocellular carcinoma and branch portal vein thrombosis. Indian J Gastroenterol 37(2):127-132PMID: 29532323. https://doi.org/ 10.1007/s12664-018-0830-4

18. Lencioni R, de Baere T, Soulen MC, Rilling WS, Geschwind JF (2016) Lipiodol transarterial chemoembolization for hepatocellular carcinoma: a systematic review of efficacy and safety data. Hepatology 64(1):106116PMID: 26765068. https://doi.org/10.1002/hep.28453

19. Song DS, Bae SH (2012) Changes of guidelines diagnosing hepatocellular carcinoma during the last ten-year period. Clin Mol Hepatol 18(3):258267PMID: 23091805. https://doi.org/10.3350/cmh.2012.18.3.258

20. Kloeckner R, Weinmann A, Prinz F, Pinto dos Santos D, Ruckes C, Dueber C, Pitton MB (2015) Conventional transarterial chemoembolization versus drug-eluting bead transarterial chemoembolization for the treatment of hepatocellular carcinoma. BMC Cancer 15:465PMID: 26059447. https:// doi.org/10.1186/s12885-015-1480-x

21. Zeeneldin AA, Salem SE, Tabashy RH, Ibrahim AA, Alieldin NH (2013) Transarterial chemoembolization for the treatment of hepatocellular carcinoma: a single center experience including 221 patients. J Egypt Natl Canc Inst 25(3):143-150PMID: 23932751. https://doi.org/10.1016/j. jnci.2013.05.003

22. Greten TF, Papendorf F, Bleck JS, Kirchhoff T, Wohlberedt T, Kubicka S, Klempnauer J, Galanski M, Manns MP (2005) Survival rate in patients with hepatocellular carcinoma: a retrospective analysis of 389 patients. $\mathrm{Br} J$ Cancer 92(10):1862-1868PMID: 15870713. https://doi.org/10.1038/sj.bjc. 6602590

23. Riaz A, Ryu RK, Kulik LM, Mulcahy MF, Lewandowski RJ, Minocha J, Ibrahim SM, Sato KT, Baker T, Miller FH, Newman S, Omary R, Abecassis M, Benson AB 3rd, Salem R (2009) Alpha-fetoprotein response after locoregional therapy for hepatocellular carcinoma: oncologic marker of radiologic response, progression, and survival. J Clin Oncol 27(34):5734-5742PMID: 19805671. https://doi.org/10.1200/JCO.2009.23.1282

24. Park WH, Shim JH, Han SB, Won HJ, Shin YM, Kim KM, Lim YS, Lee HC (2012) Clinical utility of des- $\gamma$-carboxyprothrombin kinetics as a complement to radiologic response in patients with hepatocellular carcinoma undergoing transarterial chemoembolization. J Vasc Interv Radiol 23(7):927-936PMID: 22633621. https://doi.org/10.1016/j.jvir.2012.04.021

25. Ebied OM, Federle MP, Carr BI, Pealer KM, Li W, Amesur N, Zajko A (2003) Evaluation of responses to chemoembolization in patients with unresectable hepatocellular carcinoma. Cancer 97(4):1042-1050PMID: 12569604. https://doi.org/10.1002/cncr.11111

26. Golfieri R, Renzulli M, Mosconi C, Forlani L, Giampalma E, Piscaglia F, Trevisani F, Bolondi L, Bologna Liver Oncology Group (BLOG) (2013) Hepatocellular carcinoma responding to super selective transarterial chemoembolization: an issue of nodule dimension? J Vasc Interv Radiol 24(4):509-517PMID: 23428355. https://doi.org/10.1016/j.jvir.2012.12.013

27. Jang JW, You CR, Kim CW, Bae SH, Yoon SK, Yoo YK, Kim DG, Choi JY (2010) Benefit of downsizing hepatocellular carcinoma in a liver transplant population. Aliment Pharmacol Ther 31(3):415-423PMID: 19821808. https://doi.org/10.1111/j.1365-2036.2009.04167.x

28. Halazun KJ, Hardy MA, Rana AA, Woodland DC 4th, Luyten EJ, Mahadev S, Witkowski P, Siegel AB, Brown RS Jr, Emond JC (2009) Negative impact of neutrophil-lymphocyte ratio on outcome after liver transplantation for hepatocellular carcinoma. Ann Surg 250(1):141-151PMID: 19561458. https://doi.org/10.1097/SLA.0b013e3181a77e59

29. Park H, Kim SU, Park JY, Kim DY, Ahn SH, Chon CY, Han KH, Seong J (2014) Clinical usefulness of double biomarkers AFP and PIVKA-II for subdividing prognostic groups in locally advanced hepatocellular carcinoma. Liver Int 34(2):313-321PMID: 23895043. https://doi.org/10.1111/liv.12274

30. Lai Q, Avolio AW, Manzia TM, Sorge R, Agnes S, Tisone G, Berloco PB, Rossi M (2012) Combination of biological and morphological parameters for the selection of patients with hepatocellular carcinoma waiting for liver transplantation. Clin Transpl 26(2):E125-E131PMID: 22192083. https://doi. org/10.1111/j.1399-0012.2011.01572.x

31. Jeong SO, Kim EB, Jeong SW, Jang JY, Lee SH, Kim SG, Cha SW, Kim YS, Cho YD, Kim HS, Kim BS, Kim YJ, Goo DE, Park SY (2017) Predictive factors for complete response and recurrence after transarterial chemoembolization in hepatocellular carcinoma. Gut Liver 11(3):409-416PMID: 28208001. https://doi.org/10.5009/gnl16001
32. Dohi C, Nouso K, Miyahara K, Morimoto Y, Wada N, Kinugasa H, Takeuch Y, Kuwaki K, Onishi H, Ikeda F, Nakamura S, Shiraha H, Takaki A, Okada H (2016) Potential of alpha-fetoprotein as a prognostic marker after curative radiofrequency ablation of hepatocellular carcinoma. Hepatol Res 46(9):916-923PMID: 26670077. https://doi.org/10.1111/hepr.12636

33. Rhu J, Kim JM, Choi GS, Kwon CHD, Joh JW (2018) Validation of the a-fetoprotein model for hepatocellular carcinoma recurrence after transplantation in an Asian population. Transplantation 102(8):13161322PMID: 29470357. https://doi.org/10.1097/TP.0000000000002136

\section{Publisher's Note}

Springer Nature remains neutral with regard to jurisdictional claims in published maps and institutional affiliations.

\section{Submit your manuscript to a SpringerOpen ${ }^{\circ}$ journal and benefit from:}

- Convenient online submission

- Rigorous peer review

- Open access: articles freely available online

- High visibility within the field

Retaining the copyright to your article

Submit your next manuscript at $\boldsymbol{\nabla}$ springeropen.com 